\title{
Hydrophilicity and flexibility of the spacer as critical parameters on the aggregation behavior of long alkyl chain cationic gemini surfactants in aqueous solution
}

M. Teresa Garcia ${ }^{a^{*}}$, Olga Kaczerewska ${ }^{b}$, Isabel Ribosa ${ }^{a}$, Bogumił Brycki ${ }^{\mathrm{b}}$, Paulina Materna ${ }^{\mathrm{b}}$, Małgorzata Drgas ${ }^{b}$

a Department of Chemical and Surfactants Technology, Institute of Advanced Chemistry of Catalonia, IQAC-CSIC, Jordi Girona 18-26, 08034 Barcelona Spain

${ }^{b}$ Laboratory of Microbiocides Chemistry, Faculty of Chemistry, Adam Mickiewicz University, Umultowska 89b, 61-614 Poznań, Poland "corresponding author. Phone: +34 9340061 00; fax: +34 932045904 e-mail address: teresa.garcia@iqac.csic.es 


\section{ABSTRACT}

Series of quaternary ammonium-based gemini surfactants with long alkyl chains (C12 and C18) containing different spacers and substituents attached to the polar head group have been synthesized and their aggregation properties in aqueous solution examined. The effect of the hydrophobic chain, the nature and structure of the spacer group and the polarity of the head group on the aggregation behavior of such dimeric surfactants has been investigated. The critical micelle concentration (cmc) values of gemini surfactants in aqueous solution were determined by conductivity, steady state fluorescence and potentiometric measurements. The size of aggregates formed by investigated amphiphiles above the $\mathrm{cmc}$ in aqueous solution was examined by dynamic light scattering. Gemini surfactants show cmc values significantly lower than those of comparable single chain surfactants. The tendency of trimeric surfactants with a rigid spacer to form aggregates is higher than that of the corresponding dimeric surfactants. As occurs for monomeric ionic surfactants, the $\mathrm{cmc}$ of gemini surfactants decreases with the elongation of the hydrophobic chain. However, the effect of lengthening the alkyl chain on the $\mathrm{cmc}$ depends on the structure of the spacer. C12 gemini surfactants with a rigid hydrophobic spacer exhibit $\mathrm{cmc}$ higher than those containing a flexible hydrophobic spacer. For gemini surfactants with C18 alkyl chains this effect is even more pronounced and leads to differences in $\mathrm{cmc}$ values greater than one order of magnitude. The structure of the spacer, flexible or rigid chain, has been found to be a critical parameter on the self-assembly of long chain gemini surfactants. Spherical micelles are spontaneously formed above the cmc for $\mathrm{C} 12$ gemini surfactants, whereas trimeric and $\mathrm{C} 18$ gemini surfactants seems to form vesicle-like aggregates when self-aggregation occurs.

\section{KEYWORDS}

Gemini surfactant; trimeric surfactant; spacer; aggregation behavior; critical micelle concentration; aggregation number 


\section{Introduction}

The conventional monomeric quaternary ammonium salts consist of one hydrophilic part with a quaternary nitrogen atom and one hydrophobic long alkyl chain $[1,2]$. In the last decades, oligomeric surfactants like bis and tris alkylammonium salts have been intensively investigated [1,3-8]. New multiple ammonium salts are composed of two or three amphiphilic moieties connected by a spacer [4-6]. It has been shown that dimeric quaternary ammonium salts - gemini surfactants - exhibit improved surface [7] and biological [8] activity in comparison to monomeric analogs. It means that the same effect can be reached by the use of much smaller amounts of gemini surfactants instead of the monomeric analogs, what is of fundamental importance from toxicological, ecological and economical point of view [9-11]. The main factor determining the properties of cationic surfactants is the structure of compounds. The modification of the hydrophobic alkyl chains [12] and the headgroup substituents [13] as well as the nature of the spacer $[14,15]$ allows tuning the surfactant properties. An increasing number of carbon atoms $[16,17]$ and/or hydrophilic groups $[18,19]$ have a significant effect on the critical micelle concentration $(\mathrm{cmc})$. Furthermore, the increasing length of the spacer [20] and the presence of heteroatoms (like nitrogen, oxygen, sulfur) $[10,14,21]$ or $\pi$ electron groups (like benzene ring) $[14,15]$ improve the interaction with the surface. Therefore, by structure modification a surfactant molecule with the requested properties to specific applications can be obtained [10]. The most prominent features of the surfactants are their wetting, dispersing, foaming, washing and emulsifying properties [22,23]. Surfactants are widely used in household chemistry [24], plastic, textile, paper and leather industry [25], metallurgy [26], construction, mining, petrochemical, agriculture $[27,28]$ and pharmaceutical industry [29]. The global annual turnover of anionic, cationic, nonionic and amphoteric surfactants was 33,2 billion US $\$$ in 2014 and it is estimated to be higher about $2.6 \%$ in 2020 [30]. Nowadays, the use of cationic surfactants to protect materials against corrosion and biocorrosion is especially important $[27,31,32]$. As compared to single- 
tail surfactants, the specific structure of gemini compounds enhances the intrinsic anticorrosion properties of surfactants as a result of the strong interaction between the large molecules and the surface $[33,34]$.

The hydrophobic chains form a protective layer [35]; the longer the alkyl chain the greater the corrosion inhibition efficiency [36]. According to that, C18 cationic surfactants are object of great interest for scientists investigating corrosion and reference data about their aggregation behavior are essential for designing corrosion inhibition studies.

In this work we present the results of a study of the aggregation behavior in aqueous solution of different long alkyl chain (C12 and C18) gemini surfactants with flexible spacers containing additionally oxygen or nitrogen atoms as well as rigid spacer with benzene ring. The role of the alkyl chain length and polarity of the head ammonium group in modifying the micellization properties has been also investigated and compared with that of the corresponding monomeric cationic surfactants. One of the novel aspects of this work lies in the fact that the aggregation behavior of long C18 gemini surfactants has barely been investigated. This study contributes to gain insight into the factors governing the selfassembly of gemini surfactants in aqueous solution and their comparison with monomeric and trimeric surfactants in order to obtain more efficient surfactants for surface protection.

\section{Experimental}

\subsection{Materials}

Gemini surfactants with dodecyl chains have been prepared by methods described in literature, i.e. 1,6-hexamethylene-bis( $N$-dodecyl- $N, N$-dimethylammonium) dibromide (12-612) [37], 3-oxa-1,5-pentamethylene-bis( $N$-dodecyl- $N, N$-dimethylammonium) dichloride (12-O12) [38], 3-azamethyl-1,5-bis $(N$-dodecyl- $N, N$-dimethylammonium) dibromide (3N-12) [21], 1,4-bis-[N-(1-dodecyl)-N,N-dimethylammoniummethyl]benzene dibromide (QSB2-12) [39], 
1,3,5-tris-[N-(1-dodecyl)-N,N-dimethylammoniummethyl]benzene tribromide (QSB3-12) [40], 1,6-hexamethylene-bis $(N$-dodecyl- $N$-hydroxyethyl- $N$-methylammonium) dibromide (G6-MOH12) [41].

Gemini surfactants with octadecyl chains: 1-6-hexamethylene-bis( $N$-octadecyl- $N, N$ dimethylammonium) dibromide (18-6-18), 3-oxa-1,5-pentamethylene-bis $(N$-octadecyl- $N, N$ dimethylammonium) dichloride (18-O-18), 3-azamethyl-1,5-bis $(N$-octadecyl- $N, N$ dimethylammonium) $\quad$ dibromide $\quad(3 \mathrm{~N}-18), \quad$ 1,4-bis-[N, $N$-dimethyl- $N-(1-$ octadecyl)ammoniummethyl]benzene dibromide (QSB2-18), 1,6-hexamethylene-bis( $N$ hydroxyethyl- $N$-methyl- $N$-octadecylammonium) dibromide $\quad(\mathrm{G} 6-\mathrm{MOH}-18) \quad$ and $\quad 1,6-$ hexamethylene-bis( $N, N$-dihydroxyethyl- $N$-octadecylammonium) dibromide (G6-DOH-18) were prepared according to the procedures described below:

18-6-18 was synthesized by reaction of 1 equivalent of 1,6-dibromohexane ( $7 \mathrm{mmol}$; $1.78 \mathrm{~g})$ (Aldrich) with 2 equivalents of $N$-octadecyl- $N, N$-dimethylamine $(14 \mathrm{mmol} ; 3.91 \mathrm{~g}$ ) (TCl) by stirring at room temperature for $4 \mathrm{~h}$. A white solid was obtained. The crude product was crystallized from acetonitrile and dried over $\mathrm{P}_{4} \mathrm{O}_{10}$, yield: $95 \%$; ${ }^{1} \mathrm{H} \mathrm{NMR}$ in $\mathrm{CDCl}_{3}$ (Varian $400 \mathrm{MHz}): 0.95$ ppm (t, 6H); 1.21-1.39 ppm (m, 60H); 1.57 ppm (m, 4H); 1.76 ppm (m, 4H); 2.10 ppm (m, 4H); 3,38 ppm (s, 12H); 3.50 ppm (t, 4H); 3.75 ppm (t, 4H).

18-0-18 was synthesized by reaction of 1 equivalent of bis(2-chloroethyl) ether (4.7 mmol; $0.67 \mathrm{~g})$ (Aldrich) with 4 equivalents of $\mathrm{N}$-octadecyl- $\mathrm{N}, \mathrm{N}$-dimethylamine $(18.8 \mathrm{mmol}$; $5.58 \mathrm{~g}$ ) (Aldrich) by heating in n-propanol for $30 \mathrm{~h}$. After heating $40 \mathrm{~mL}$ of acetone was added. A white solid was obtained. The crude product was washed with diethyl ether and dried over $\mathrm{P}_{4} \mathrm{O}_{10}$, yield: $80 \%$; ${ }^{1} \mathrm{H}$ NMR in $\mathrm{CDCl}_{3}$ (Varian $400 \mathrm{MHz}$ ): 0.88 ppm (t, 6H), 1.281.36 ppm (m, 60H), 1.72 ppm (m, 4H), 3.60 ppm (s, 12H); 3.67 ppm (t, 4H), 4.02 ppm (t, 4H), 4.30 ppm (t, 4H).

$3 \mathrm{~N}-18$ was synthesized by reaction of 1 equivalent of $N, N, N^{\prime}, N^{\prime}, N^{\prime \prime}-$ pentamethyldiethylenetriamine (11 mmol; $2 \mathrm{~g})$ (Aldrich) with 3 equivalents of 1 bromooctadecane (33 mmol; $10.99 \mathrm{~g}$ ) (Aldrich) by heating in acetonitrile for $30 \mathrm{~h}$. A white solid was obtained. The crude product was crystallized from acetonitrile and dried over 
$\mathrm{P}_{4} \mathrm{O}_{10}$, yield: $98 \%$; ${ }^{1} \mathrm{H} \mathrm{NMR}$ in $\mathrm{CDCl}_{3}($ Varian $300 \mathrm{MHz}): 0.88 \mathrm{ppm}(\mathrm{t}, 6 \mathrm{H}), 1.19-1.38$ ppm (m, 60H), 1.73 ppm (m, 4H), 2.53 ppm (s, 3H), 3.17 ppm (t, 4H), 3.42 ppm (s, 12H), 3.59 ppm (t, 4H), 3.97 ppm (t, 4H).

QSB2-18 was synthesized by reaction of 2 equivalents of $N, N$-dimethyl- $N$ octadecylamine $(3.74 \mathrm{mmol}, 1.11 \mathrm{~g})(\mathrm{TCl})$ with 1 equivalent of 1,4-dimethylbenzene (1.89 mmol, $0.5 \mathrm{~g}$ ) by heating in 1-propanol for $10 \mathrm{~h}$. A white solid was obtained. The crude product was recrystallized from a mixture of acetone/methanol (10:1) and dried over $\mathrm{P}_{4} \mathrm{O}_{10}$, yield: 90\%; ${ }^{1} \mathrm{H}$ NMR in $\mathrm{CD}_{3} \mathrm{OD}$ (Bruker $600 \mathrm{MHz}$ ): 7.74 ppm (s, 4H), $4.64 \mathrm{ppm}(\mathrm{s}, 4 \mathrm{H}), 3.39$ ppm (t, 4H), 3.1 ppm (s, 12H), 1.91 ppm (m, 4H), 1.42-1.29 ppm (m, 60H), 0.9 ppm (t, 6H).

G6-MOH-18 and G6-DOH-18 were synthesized by reaction of 1 equivalent of 1,6dibromohexane $(25 \mathrm{mmol}, 6.1 \mathrm{~g})$ (Aldrich) with 2 equivalents of $N$-hydroxyethyl- $N$-methyl- $N$ octadecylamine $(50 \mathrm{mmol}, 16.35 \mathrm{~g})$ or $N, N$-dihydroxyethyl- $N$-octadecylamine $(50 \mathrm{mmol}, 17.85$ g), by heating in acetonitrile for $60 \mathrm{~h}$ and $69 \mathrm{~h}$, respectively. White solids were obtained. The crude products were crystallized from a mixture of chloroform/methanol and dried over $\mathrm{P}_{4} \mathrm{O}_{10}$, yield: G6-MOH-18: 60 \%, G6-DOH-18: 65 \%; ${ }^{1} \mathrm{H}$ NMR in THF: 0.92 ppm (t, 6H), 1.86 ppm and 1.35 ppm (m, 68H), 1.97 ppm (m, 4H), 3.24 ppm (s, 6H), 3.49 ppm (t, 8H), 3.74 ppm (t, 4H), 4.40 ppm (t, 4H) for G6-MOH-18 (Varian $400 \mathrm{MHz}$ ) and $0.92 \mathrm{ppm}(\mathrm{t}, 6 \mathrm{H}), 1.85 \mathrm{ppm}$ and 1.35 ppm (m, 64H), 1.95 ppm (m, 8H), 3.59 ppm (t, 8H), 3.85 ppm (t, 8H), 4.39 ppm (t, 8H) for G6-DOH-18 (Varian $300 \mathrm{MHz}$ ).

The molecular structure of tested gemini and trimeric cationic surfactants are given in Table 1. 
Table 1. Structures of gemini and trimeric quaternary ammonium surfactants.

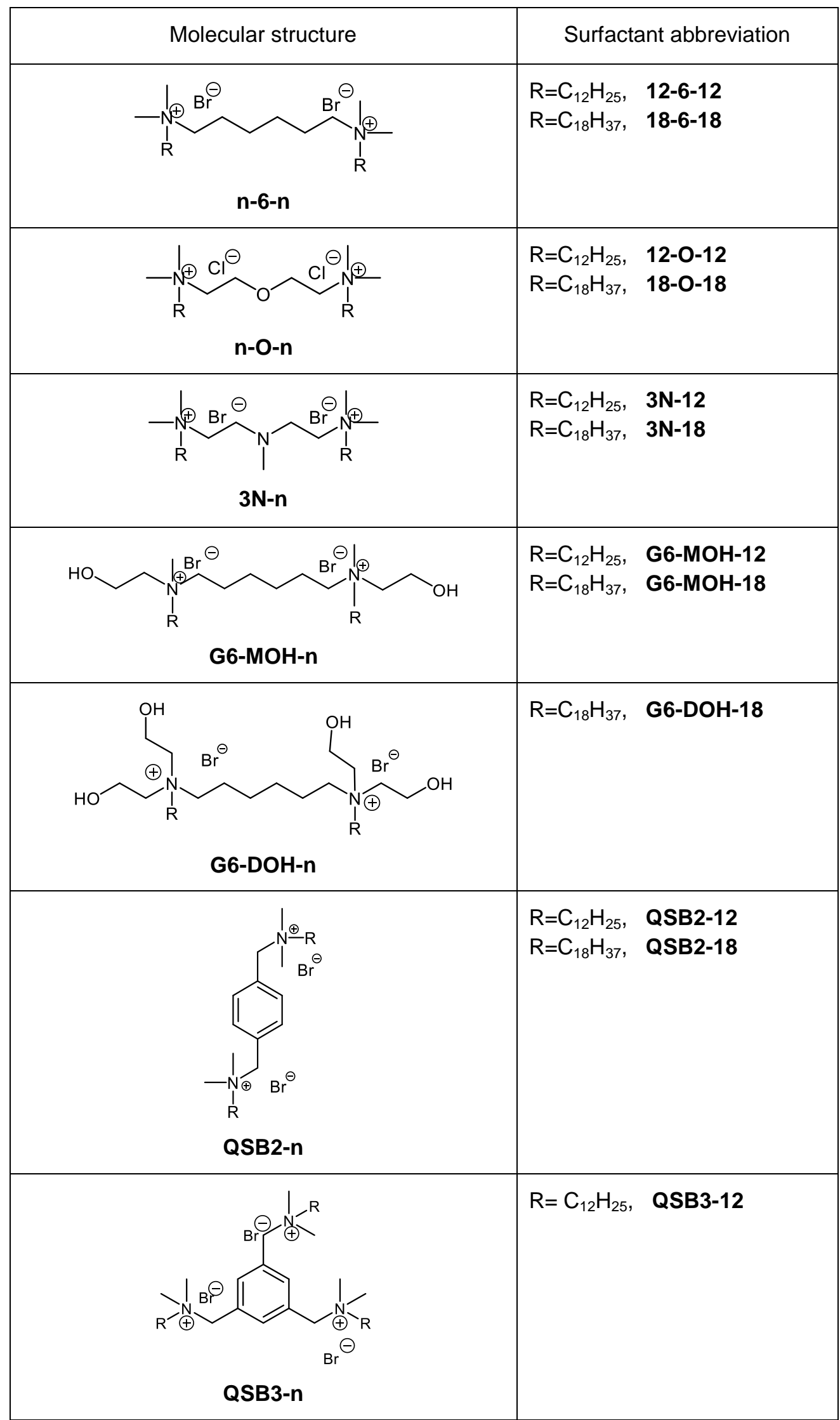




\subsection{Methods}

\subsubsection{Conductometry}

Conductivity was measured at constant temperature (35 ${ }^{\circ} \mathrm{C}$ or $45^{\circ} \mathrm{C}$ ) using an Orion Conductivity Cell 913005MD with epoxy/graphite electrode in conjunction with a Thermo Orion 5 Star multiparameter instrument with a cell constant of $0.475 \mathrm{~cm}^{-1}$.

\subsubsection{Fluorimetry}

Steady-state fluorescence measurements were performed using a Shidmazu RF 540 spectrofluorometer equipped with a thermostated cell holder at $35^{\circ} \mathrm{C}$ for most of the surfactants (for QSB2-n and QSB3-12 at $45^{\circ} \mathrm{C}$ ). Both excitation and emission band slits were fixed at $2 \mathrm{~nm}$. All date were acquired using quartz cells with $1 \mathrm{~cm}$ path length. Pyrene was used as the polarity probe. The fluorescence emission spectra of pyrene dissolved in aqueous solutions of tested gemini surfactants were recorded from 340 to $450 \mathrm{~nm}$ after excitation at $332 \mathrm{~nm}$. Pyrene exhibits fine structure in $370-400 \mathrm{~nm}$ region of the steady-state fluorescence emission spectra. The nature and the intensity of the peaks are dependent on the polarity of the environment. The ratio of the first $(\lambda=374 \mathrm{~nm})$ to the third $(\lambda=384 \mathrm{~nm})$ vibronic peaks, i.e., $I_{1} / I_{3}$, shows the greatest solvent dependency, and hence, can be used to obtain the cmc of the gemini surfactants in water. All the tested surfactants were prepared at different concentrations in aqueous solution containing $1 \times 10^{-6} \mathrm{M}$ of pyrene. In addition, a fluorescence quenching experiment was carried out to determine the aggregation number of the micelles. Pyrene was used as fluorescent probe and cetyl pyridinium chloride as quencher. To avoid the formation of pyrene excimers, the pyrene concentration was maintain at low level $\left(1 \times 10^{-6} \mathrm{M}\right)$ and concentration of the probe and quencher was adjusted to maintain Poisson distribution [42]. 


\subsubsection{Potentiometry}

The potential changes were measured at $35^{\circ} \mathrm{C}$ for G6-DOH-18 and QSB2-12 and at $45^{\circ} \mathrm{C}$ for QSB3-12 using a bromide ion selective electrode (9635BNWP, Thermo Orion) in conjunction with a Thermo Orion 5 Star multiparameter instrument.

\subsubsection{Dynamic light scattering (DLS) measurements}

Dynamic light scattering (DLS) measurements were conducted at $308.15 \mathrm{~K}$ using a light scattering apparatus (Zetasizer, Nano-ZS Malvern Instruments) with a He-Ne laser (633 nm, $4 \mathrm{~mW}$ ) equipped with a built-in temperature controller. Thirty repeated measurements were performed for each sample. The data evaluation of the dynamic light scattering measurements was performed with the CONTIN algorithm and data are reported with an uncertainty of less than $7 \%$.

\section{Results and discussion}

\subsection{Conductometry}

The variation of the specific conductivity in aqueous solutions of the surfactants as a function of the concentration was investigated. Conductivity measurements were carried out at $35 \stackrel{\circ}{\circ}$ excepting for QSB2-18 and QSB3-12. For the latter surfactants the measurements were performed at $45^{\circ} \mathrm{C}$ due to their low solubility in water. Representative conductometric profiles of tested gemini surfactants are displayed in Figure 1. 

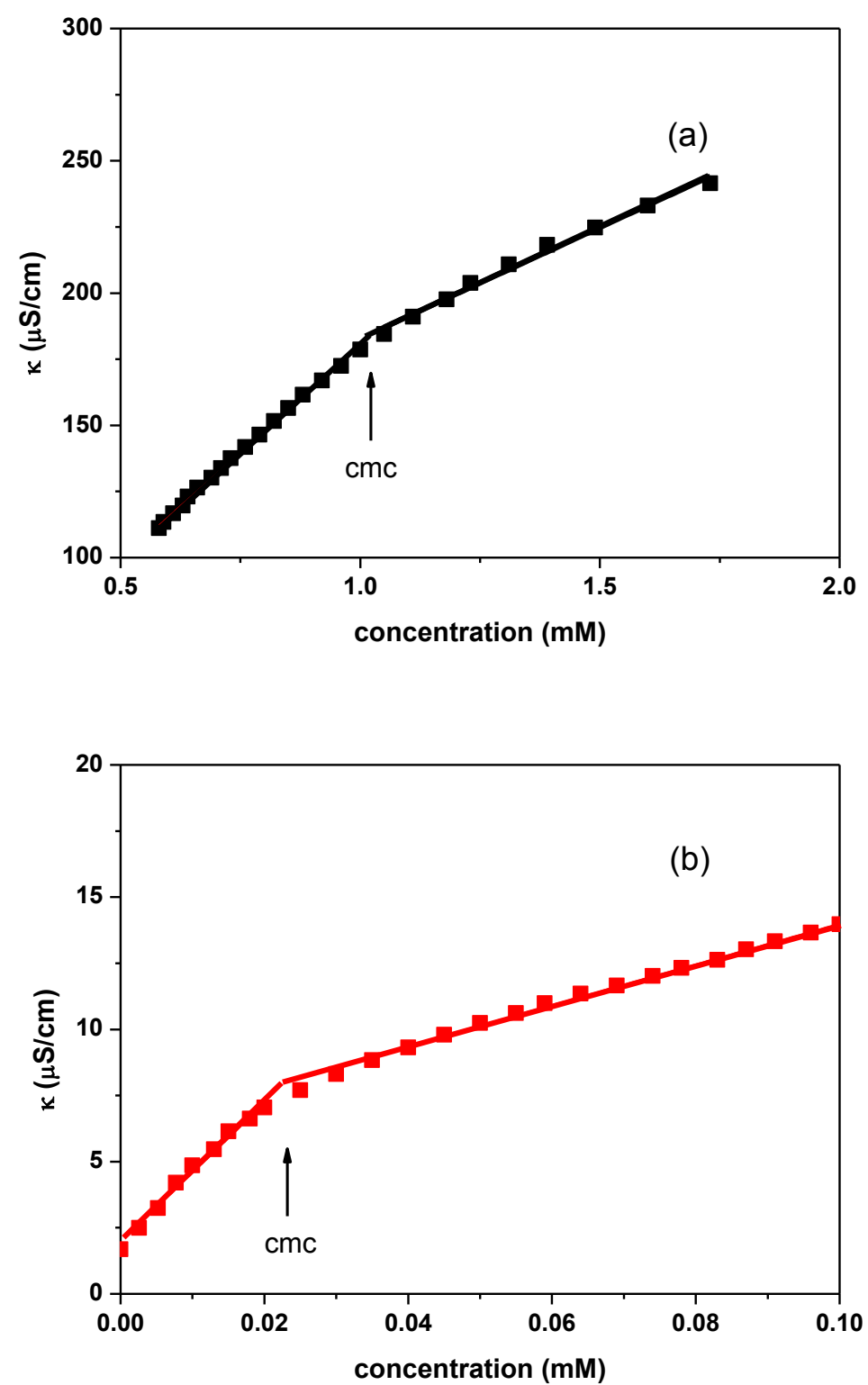

Fig. 1. Specific conductivity $(\mathrm{k})$ versus gemini surfactant concentration in water at $35^{\circ} \mathrm{C}$ : (a) $3 \mathrm{~N}-12$ and (b) 18-6-18.

The conductivity values fit into two straight lines of different slope in pre- and postmicellization regions, being the slope of the pre-micellization region higher than in the post micellization zone. The abrupt change in the slope is due to the binding of some counterions to the micelle and to the lower mobility of the micelles compared to surfactant monomers. The corresponding critical micelle concentration $(\mathrm{cmc})$ value was determined from the location of the break point $[43,44]$. The ratio of the slope of linear regions above and below 
the $\mathrm{cmc}$ gives an estimate of the counterion binding parameter, $\beta$. This parameter estimates the counterions that are contained in the Stern layer to counterbalance the electrostatic force that opposes aggregates formation. The standard Gibbs energy of micellization $\left(\Delta \mathrm{G}^{\circ}{ }_{\text {mic }}\right)$ gives information about if the process of forming micelles is spontaneous and can be calculated using the literature expression [60]:

$$
\Delta \mathrm{G}^{\circ} \mathrm{mic}=2 \mathrm{RT}(1 / 2+\beta) \ln c m c-\mathrm{RT} \ln 2
$$

where $\beta$ is the fraction of charges of micellized univalent surfactant ions neutralized by micelle-bound univalent counterions, the $\mathrm{cmc}$ is expressed in $\mathrm{mol} / \mathrm{dm}^{3}, \mathrm{~T}$ is the temperature in Kelvin (K) and $R$ is the gas constant. The values of $\mathrm{cmc}, \beta$ and $\Delta \mathrm{G}^{\circ}{ }_{\text {mic }}$ are presented in Table 2.

Table 2. Critical micelle concentration ( $\mathrm{cmc}$ ), counterion binding parameter $(\beta)$ and Gibbs free energy of micellization $\left(\Delta \mathrm{G}^{\circ} \mathrm{mic}\right)$ of gemini and trimeric surfactants in aqueous solution obtained from conductivity measurements.

\begin{tabular}{llllc} 
& Temperature $(\mathbf{-} \mathbf{C})$ & $\mathbf{c m c}(\mathbf{m M})$ & $\boldsymbol{\beta}$ & $\mathbf{\Delta G}^{\circ} \mathbf{m i c}(\mathbf{k J} / \mathbf{m o l})$ \\
\hline $\mathbf{1 2 - 6 - 1 2}$ & 35 & $0.98 \pm 0.01$ & 0.40 & -33.7 \\
$\mathbf{1 8 - 6 - 1 8}$ & 35 & $0.022 \pm 0.001$ & 0.73 & -69.4 \\
$\mathbf{1 2 - 0 - 1 2}$ & 35 & $1.72 \pm 0.01$ & 0.38 & -30.5 \\
$\mathbf{1 8 - 0 - 1 8}$ & 35 & $0.044 \pm 0.001$ & 0.56 & -56.3 \\
$\mathbf{3 N - 1 2}$ & 35 & $1.06 \pm 0.02$ & 0.53 & -38.2 \\
$\mathbf{3 N - 1 8}$ & 35 & $0.076 \pm 0.001$ & 0.29 & -40.2 \\
G6-MOH-12 & 35 & $1.05 \pm 0.01$ & 0.36 & -36.5 \\
G6-MOH-18 & 35 & $0.046 \pm 0.004$ & 0.48 & -51.9 \\
G6-DOH-18 & - & - & - & - \\
QSB2-12 & 35 & $1.21 \pm 0.01$ & 0.59 & -39.3 \\
QSB2-12 & 45 & $1.35 \pm 0.02$ & 0.51 & $-42,2$ \\
QSB2-18 & 45 & $0.30 \pm 0.01$ & 0.15 & -28.8 \\
QSB3-12 & 45 & $0.47 \pm 0.03$ & 0.32 & -49.7
\end{tabular}

$\left({ }^{*}\right)$ The micellization parameters of G6-DOH-18 could not be investigated by conductivity measurements due to the absence of significant changes in the slope with increasing surfactant concentration. 
The investigated gemini surfactants show significantly lower $\mathrm{cmc}$ values (Table 2) than their corresponding monomeric counterparts. Thus, dimeric surfactants, $12-6-12,12-\mathrm{O}-12$ and $3 \mathrm{~N}-$ 12 have $\mathrm{cmc}$ values one order of magnitude smaller than their monomeric analogues, $N$ dodecyl- $N, N, N$-trimethylammonium bromide and $N$-dodecyl- $N, N, N$-trimethylammonium chloride, with reported $\mathrm{cmc}$ values of $16 \mathrm{mM}[45,46]$ and $18-21 \mathrm{mM}[46,47]$, respectively. The cmc values of QSB2-12 and QSB3-12 are three and six fold, respectively, lower than the reported value of $3 \mathrm{mM}$ for the monomeric surfactant $N$-dodecyl- $N$-benzyl- $N, N$ dimethylammonium bromide [48]. G6-MOH-12 gemini surfactant has a cmc fifteen times lower than the value of $16 \mathrm{mM}$ corresponding to the monomeric surfactant $N$-hydroxyethyl$N, N$-dimethyl- $N$-dodecylamine bromide [49].

The comparison of results obtained (Table 2) and those previously reported for similar surfactants has been mainly focused on the C12 gemini compounds because of the few data available for $\mathrm{C} 18$ dimeric surfactants. The $\mathrm{cmc}$ value obtained for $12-6-12$ is in good agreement with the $\mathrm{cmc}$ value of $1.03 \mathrm{mM}$ at $25{ }^{\circ} \mathrm{C}$ reported by Grosmaire and Zana [50] from conductivity measurements. 12-0-12 dimeric surfactant displays a $\mathrm{cmc}$ value slightly higher than the reported values of $1.02 \mathrm{mM}\left(25^{\circ} \mathrm{C}\right)$ [51] and $1.35 \mathrm{mM}\left(50{ }^{\circ} \mathrm{C}\right)$ [14] obtained by conductivity. This fact can be partially attributed to the different halide counterion, chloride instead of bromide, which trends to increase the cmc because of its lower polarizability [52]. A good correlation is found between the cmc value obtained for $3 \mathrm{~N}-12$ gemini surfactant and the values reported by Wettig [21], 0.97 and $1.14 \mathrm{mM}$, from conductivity and surface tension measurements, respectively. Regarding gemini surfactants with rigid alkyl chain, the $\mathrm{cmc}$ value obtained for QSB2-12 is close to the 1.60 and $1.52 \mathrm{mM}$ values (both at $50{ }^{\circ} \mathrm{C}$ ) determined by conductivity and reported by Zana and Wang, respectively [53,54]. With regard to the longer gemini surfactants here studied, 18-6-18 exhibits a cmc close to the values determined by conductivity $(0.018 \mathrm{mM})$ and fluorescence $(0.021 \mathrm{mM})[55]$ for a gemini surfactant containing oleyl chains and the same spacer chain, 18:1-6-18:1. Likewise, the 18- 
6-18 cmc value is similar but slightly higher than $0.012 \mathrm{mM}$, the $\mathrm{cmc}$ value obtained by conductivity for a gemini surfactant with the same alkyl chain length but a longer polymethylene spacer group, 18-8-18 [53]. Nevertheless, concerning to G6-MOH-12, the cmc value here obtained differs significantly from the $\mathrm{cmc}$ value $(0.029 \mathrm{mM})$ reported by Borse et al. [49] for the structurally related compound G4-MOH-12. Those authors reported a significant decrease in the $\mathrm{cmc}$ by replacement of a methylene group by an ethyl hydroxyl group whereas a slight increase in the $\mathrm{cmc}$ value has been observed in the present work.

Regarding the effect of the hydrophobic chain, the $\mathrm{cmc}$ of the gemini surfactants studied decreases with lengthening of the alkyl chain linked to the hydrophilic group (Table 2), similarly to monomeric cationic surfactants $[45,48]$ and other gemini surfactants [16]. As it can be seen in Table 2, gemini surfactants with C18 chains and flexible spacers form micelles at a concentration range 15-50 times lower than $\mathrm{C} 12$ analogues. However, the effect of the elongation of the alkyl chain on the cmc becomes less pronounced for gemini surfactants with rigid $p$-xylyl spacer and thus, QSB2-18 has a cmc value only five fold lower than the QSB2-12 homologue.

Moreover, the effect of different types of flexible and rigid spacers on the micellization properties of a series of gemini surfactants with the same head groups, the same hydrophobic chains and approximately the same length of spacer has been examined in this work. Accordingly, the aggregation behavior of quaternary ammonium-based gemini surfactants with $\mathrm{C} 12$ and $\mathrm{C} 18$ alkyl chains containing as spacers a polymethylene chain (n-6$n$ ), an ethoxylated chain (n-O-n), an aza-substituted chain (3N-n) and a $p$-xylyl spacer (QSB2-n) has been investigated. With regard the flexible spacers, the addition of an oxygen atom or an aza- group increases the hydrophilicity of the spacer what causes a better solubility in water. Wettig et al. [21] reported that it leads to spacers preferably located at the air-water or micelle-water interfaces. The comparison of the $\mathrm{cmc}$ of gemini surfactants containing flexible spacers ( $n-6-n, n-O-n$ and $3 N-n$ ) (Table 2) shows that the cmc values found for ethoxylated and aza-substituted groups were greater than for the hydrophobic polymethylene spacer. The increased hydrophilicity of the spacer led to an increase of the 
surfactant $\mathrm{cmc}$. The higher $\mathrm{cmc}$ values observed for ethoxylated and aza-substituted series could be attributed, respectively, to an increase of the size and hydrophilicity of the molecule and to increased steric repulsion with respect to packing at the surface of the micelle $[8,21,52]$.

The structure of the spacer, i.e., flexible or rigid chain, has been found to be a critical parameter on the self-assembly of the gemini surfactant molecules. The $\mathrm{C} 12$ gemini surfactant with the rigid hydrophobic $p$-xylyl spacer exhibit a significantly higher $\mathrm{cmc}$ value than the same gemini surfactant containing a hydrophobic flexible spacer (Table 2). For gemini surfactants with $\mathrm{C} 18$ alkyl chain the effect of the spacer is even more pronounced leading to differences in cmc values greater than one order of magnitude. These results are consistent with those reported by Wang and Han [14,56] for gemini surfactants with C12 hydrophobic chains. As suggested by Rosen [57] the rigidity of the hydrophobic $p$-xylyl group could prevent its removal from contact with the aqueous phase by incorporation into the interior of the micelle and this would inhibit micelle formation increasing the $\mathrm{cmc}$ values.

Analyzing the effect of replacing a methyl group by an ethyl hydroxyl substituent on the aggregation behavior, it can be observed that the $\mathrm{cmc}$ increases slightly with increasing the polarity of the head group (Table 2). This result agrees with that reported by Jordan et al. for comparable monomeric surfactants [58].

Regarding the aggregation behavior of QSB3-12 (Table 2), the trimeric surfactant exhibits higher tendency to aggregate than the corresponding dimeric surfactant QSB2-12. This suggests that the incorporation of an additional hydrophobic alkyl chain enhances selfassembly of the surfactant molecule despite the strong electrostatic repulsion among multiple quaternary ammonium head groups. The cmc value for QSB3-12 is of the same order of magnitude than that reported in literature for a $\mathrm{C} 12$ analogous trimeric surfactant with a tris(2-aminoethyl)amine core as spacer [59].

For the gemini surfactants with flexible spacers, n-6-n, n-O-n, and G6-MOH-n, the values of $\beta$ increased with increasing the alkyl chain length. It means that the counterion is more tightly bound to the aggregate as the carbon chain becomes longer and indicates the 
formation of more compact micelles in the case of $\mathrm{C} 18$ homologous as a consequence of increased shielding of the electrostatic interactions between the ionic head groups. For $3 \mathrm{~N}-\mathrm{n}$ and QSB2-n surfactants, the degree of counterion binding decreases on going from $\mathrm{C} 12$ to C18 homologues. However, in spite of the looser binding of counterion, the elongation of the alkyl chain length increases the hydrophobic character of the surfactant with consequent decrease in cmc. Similar observations were also made in the case of monomeric ammoniumbased cationic surfactants, where an increase in the alkyl chain length leads to a decrease in the $\mathrm{cmc}$ along with a decrease in counterion binding as a consequence of an increase in the area per head group of the surfactant ion at the interface of the micelle [52].

The standard Gibbs energy of micellization is negative (Table 2) for all the surfactants what means that the process of forming aggregates is spontaneous. Moreover, it was observed that the value of $\Delta \mathrm{G}^{\circ}{ }_{\text {mic }}$ decreases when the carbon chain is getting longer indicating that the micellization process is governed by hydrophobic interactions.

\subsection{Fluorimetry}

Steady-state fluorescence measurements using pyrene as the solvatochromic probe were applied to study the micelle aggregation behavior of tested gemini surfactants. The intensity ratio of the first to the third vibronic peaks of pyrene $\left(I_{1} / I_{3}\right)$ was measured as a function of surfactant concentrations. Representative results are shown in Figures 2 and 3 for $n-6-n$ and G6-MOH-n gemini surfactants. 


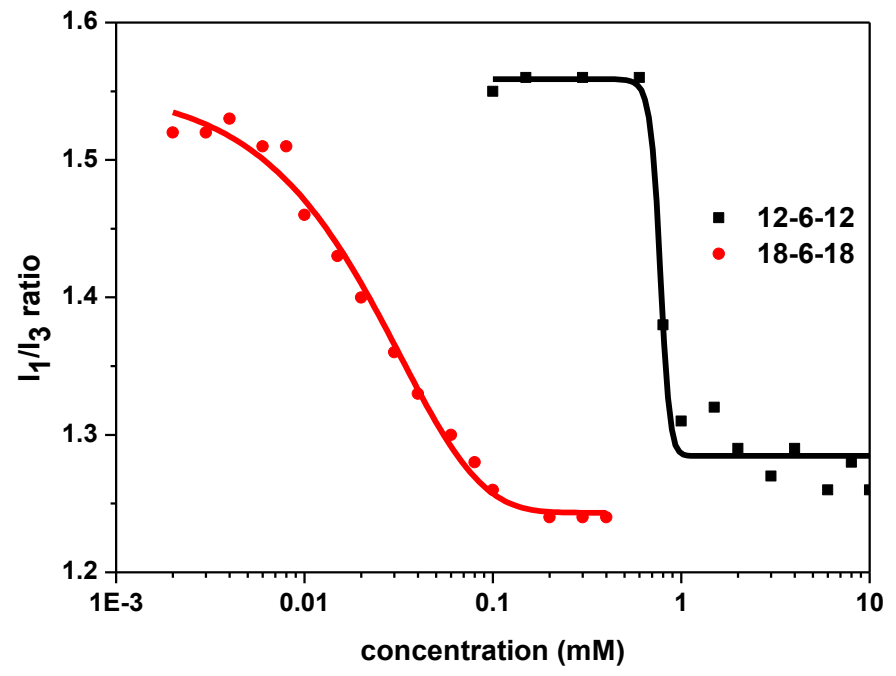

Fig. 2. Variation of the $I_{1} / I_{3}$ ratio with the surfactant concentration for $n-6-n$ gemini surfactants in aqueous solution at $35^{\circ} \mathrm{C}$.

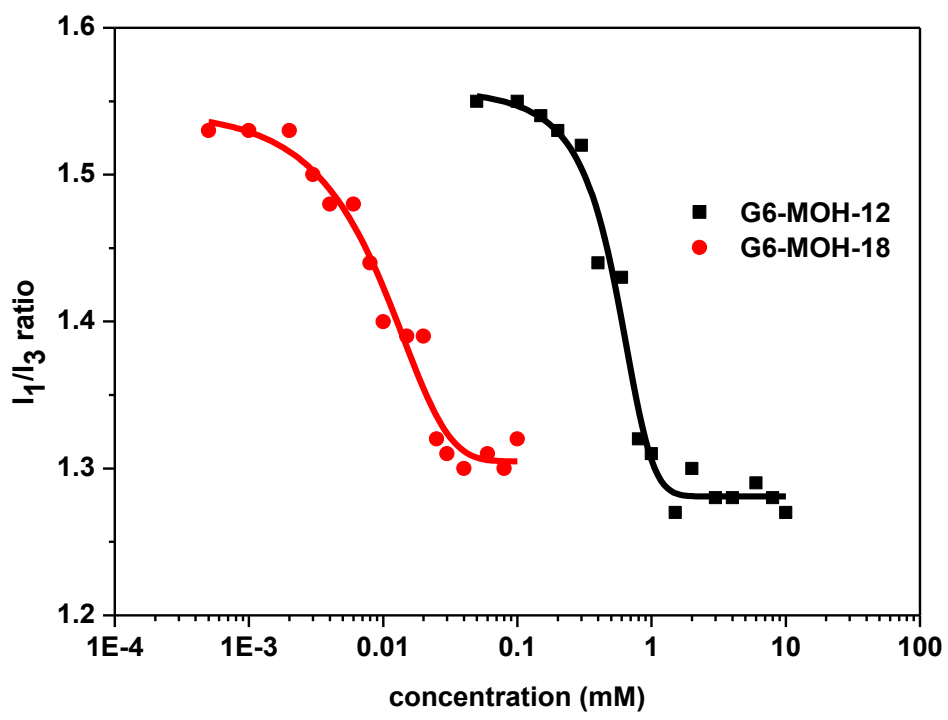

Fig. 3. Variation of the $I_{1} / I_{3}$ ratio with the surfactant concentration for G6-MOH-n gemini surfactants in aqueous solution at $35^{\circ} \mathrm{C}$.

The abrupt sigmoidal decrease in $I_{1} / I_{3}$ intensity ratio indicates the formation of surfactants aggregates and the preferential residence of pyrene molecules in hydrophobic regions of micelles. The $\mathrm{cmc}$ values were taken as the concentration that corresponds to the midpoint of the transition [61] and are shown in Table 3. 
Table 3. Critical micelle concentration (cmc) by fluorescence and potentiometric measurements

\begin{tabular}{cccc} 
Surfactant & Temperature $\left({ }^{\circ} \mathrm{C}\right)$ & \multicolumn{3}{c}{$\mathbf{c m c}(\mathbf{m M})$} \\
$\mathbf{1 2 - 6 - 1 2}$ & 35 & $0.76 \pm 0.03$ & - \\
$\mathbf{1 8 - 6 - 1 8}$ & 35 & $0.02 \pm 0.01$ & - \\
$\mathbf{1 2 - 0 - 1 2}$ & 35 & $1.70 \pm 0.02$ & - \\
$\mathbf{1 8 - 0 - 1 8}$ & 35 & $0.03 \pm 0.01$ & - \\
$\mathbf{3 N - 1 2}$ & 35 & $0.71 \pm 0.04$ & - \\
3N-18 & 35 & $0.04 \pm 0.01$ & - \\
G6-MOH-12 & 35 & $0.56 \pm 0.06$ & - \\
G6-MOH-18 & 35 & $0.011 \pm 0.005$ & - \\
G6-DOH-18 & 35 & $0.02 \pm 0.01$ & $0.09 \pm 0.01$ \\
QSB2-12 & 45 & $0.95 \pm 0.09$ & $0.93 \pm 0.05$ \\
QSB2-18 & 45 & $0.13 \pm 0.02$ & - \\
QSB3-12 & 45 & $0.54 \pm 0.01$ & $0.68 \pm 0.02$ \\
\hline
\end{tabular}

Fluorimetry proved to be a suitable technique for determining the self-aggregation concentration of all the investigated dimeric and trimeric surfactants, including the G6-DOH18 that could not be previously studied by conductometry. The cmc values derived from fluorescence measurements (Table 3) are consistent with those obtained by conductivity measurements (Table 2). The replacement of the methyl group (G6-MOH-18) by an ethyl hydroxyl group (G6-DOH-18) results in a slight increase in the cmc value (Table 3 ). Comparing dimeric, QSB2-12, and trimeric, QSB3-12, surfactants, the incorporation of an additional ammonium group and a $\mathrm{C} 12$ alkyl chain promotes aggregation and halves the critical micelle concentration as it was already observed by conductivity measurements. 
The static fluorescence quenching method has been applied for determining the micellar aggregation number of $\mathrm{C} 12$ gemini surfactants. The equation used for obtaining the aggregation number $\left(\mathrm{N}_{\text {agg }}\right)$ was [62]:

$$
\ln \left(I_{O} / I\right)=\left(N_{a g g} C_{Q}\right) /\left(C_{S}-c m c\right)
$$

in which $\mathrm{I}$ and $\mathrm{I}_{0}$ are the fluorescence intensities with and without quencher, respectively, at a wavelength of $374 \mathrm{~nm} ; \mathrm{C}_{\mathrm{S}}$ and $\mathrm{C}_{\mathrm{Q}}$ are the concentrations of investigated surfactants and the quencher, respectively. The method could not be applied to the trimeric surfactant (QSB3-12) and gemini surfactants with octadecyl chains because they form vesicle-like aggregates above $\mathrm{cmc}$ (see section 3.4 Dynamic light scattering measurements). From the slope of the linear plot between $\ln \left(\mathrm{I}_{0} / \mathrm{I}\right)$ and $\mathrm{C}_{\mathrm{Q}}$ in micellar solutions of the gemini surfactants investigated (Fig. 4), the aggregation number was determined.

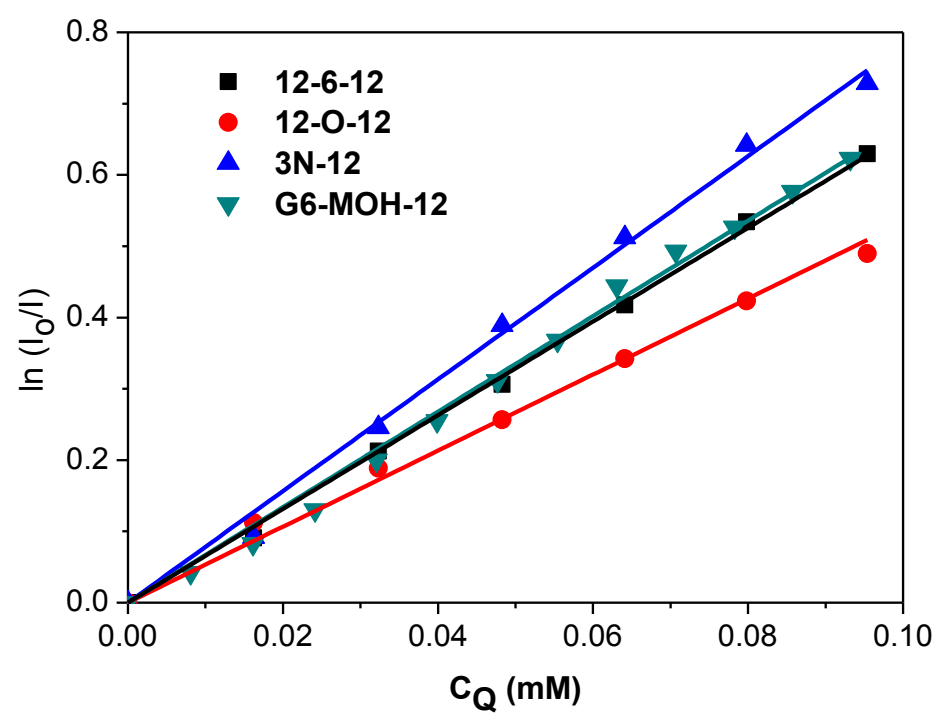

Fig. 4. Variation of In $\left(\mathrm{I}_{0} / \mathrm{I}\right)$ as a function of quencher concentration

The aggregation number $\left(\mathrm{N}_{\text {agg }}\right)$ obtained for the $\mathrm{C} 12$ gemini surfactants containing a flexible spacer was 17, 20, 21 and 21 for 12-6-12, 12-O-12, 3N-12 and G-MOH-12, respectively. The results here obtained are consistent with those reported by Wang et al. [54] for 12-6-12 and 12-O-12 ( $\mathrm{N}_{\mathrm{agg}}=19$ and 21, respectively) and by Pisarcik et al. [63] for 12-6-12 ( $\left.\mathrm{N}_{\mathrm{agg}}=18-20\right)$. The $\mathrm{N}_{\text {agg }}$ for $3 \mathrm{~N}-12$ is lower than that reported by Wettig et al. [21] $\left(\mathrm{N}_{\mathrm{agg}}=38\right)$. The low 
aggregation numbers obtained suggest spherical micelles. It can be observed a slight increase in the number of surfactants molecules forming the micelles with increasing the hydrophilicity of the spacer or the polarity of the ammonium head group.

\subsection{Potentiometry}

In order to compare the aggregation concentration of dimeric QSB2-12 and trimeric QSB3-12 surfactants and to confirm the cmc of $\mathrm{G} 6-\mathrm{MOH}-18$, potentiometric measurements using a $\mathrm{Br}^{-}$ selective electrode were performed. Figure 5 illustrates the relationship between the electrode potential $(\Delta \mathrm{E})$ and the surfactant concentration for $\mathrm{G} 6-\mathrm{MOH}-18$.

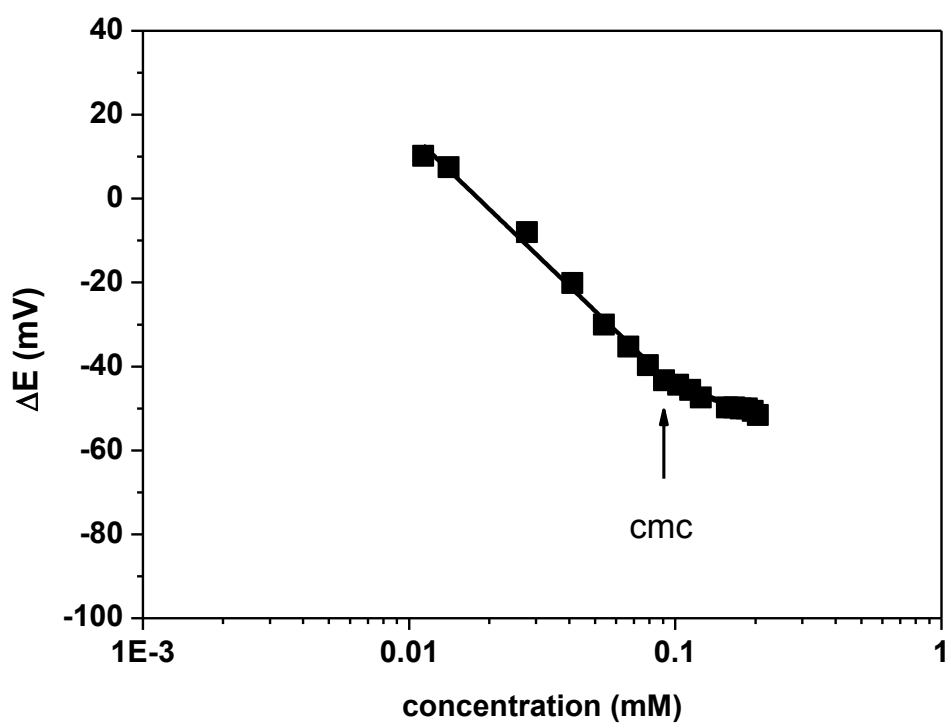

Fig. 5. Variation of the electrode potential $(\Delta \mathrm{E})$ as a function of $\mathrm{G} 6-\mathrm{DOH}-18$ concentration in aqueous solution at $35^{\circ} \mathrm{C}$

As observed, a good linearity is obtained for surfactant solutions below the $\mathrm{cmc}$, while above the $\mathrm{cmc}$ the plot remarkably deviates from linearity. The $\mathrm{cmc}$ values were determined as break points in the $\Delta \mathrm{E}-\log \mathrm{C}$ plot (Table 3) and are consistent with those obtained by conductivity (Table 2) and fluorescence (Table 3) measurements. The results obtained by 
potentiometry confirm the higher tendency to aggregate of trimeric QSB3-12 as compared to the corresponding QSB2-12 dimeric surfactant.

\subsection{Dynamic light scattering (DLS) measurements}

Size of aggregates of the investigated gemini and trimeric surfactants in aqueous solution

was determined by dynamic light scattering (DLS) measurements. DLS measurements to obtain the hydrodynamic diameter $\left(D_{h}\right)$ of the aggregates were carried out at concentrations 3-5 times superior to the $\mathrm{cmc}$ value. Characteristic intensity- and number-weighted size distribution profiles obtained for the surfactants studied are shown in Figure 6 for some C12 and C18 gemini surfactants and the trimeric surfactant QSB3-12.
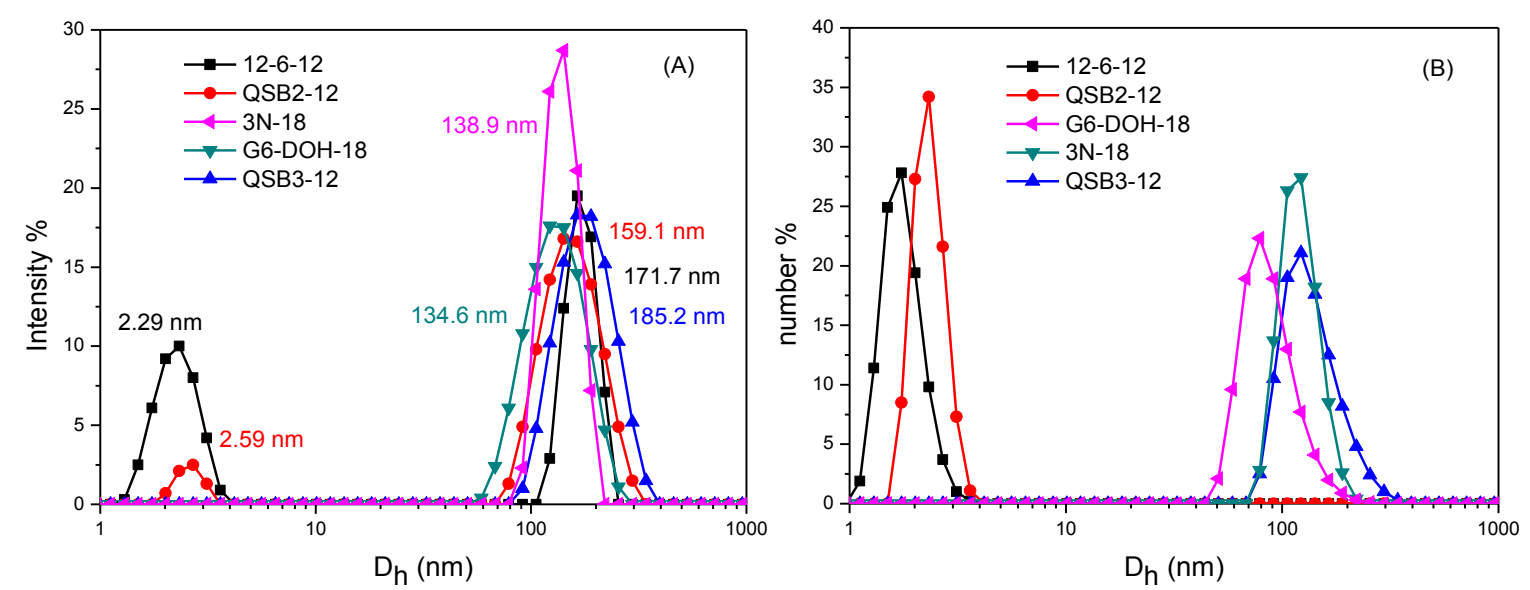

Fig. 6. Size distribution profiles of aggregates of gemini and trimeric surfactants in aqueous solution in terms of \% intensity (A) and \% number (B) obtained from DLS measurements

From intensity distribution profiles (Fig. 6A), two size distributions were obtained for gemini surfactants with dodecyl chains, one with a hydrodynamic diameter, $D_{h}$, at maximum scattering intensity in the range of $2.3-2.7 \mathrm{~nm}$ and the other one with $D_{h}$ in the range $160-270$ $\mathrm{nm}$. The smaller and larger $D_{h}$ values were assigned to the presence of spherical micelles and micellar agglomerates, respectively. Number-weighted size distributions (Fig. 6B) show that the number of small micelles is predominant against micellar agglomerates for $C_{12}$ 
gemini surfactants. The $D_{h}$ value corresponding to small micelles has therefore been considered for further discussion. $D_{h}$ values obtained for $C_{12}$ gemini surfactant micelles are consistent with the values of $2.6 \mathrm{~nm}$ and 2.0-3.5 nm reported for $12-6-12$ [64] and $\mathrm{C}_{12}$ gemini surfactants with polymethylene spacer of 4-12 carbon atoms [63], respectively, both determined by DLS. $D_{h}$ of micelles formed by dimeric surfactants with dodecyl chains were found to be somewhat lower than twice fold the hydrocarbon extended chain length of the cation (around $1.7 \mathrm{~nm}$ for the dodecyl hydrocarbon chain according to Tanford [65]) which suggests the formation of tightly packed spherical micelles. The average particle sizes for the studied $\mathrm{C}_{12}$ dimeric surfactants at concentrations three times superior to the $\mathrm{cmc}$ are: 2.3 , 2.6, 2.7, 2.5 and $2.6 \mathrm{~nm}$ for 12-6-12, 12-O-12, 3N-12, G6-MOH-12 and QSB2-12, respectively. The average particle sizes for the trimeric surfactant QSB3-12 ( $\left.D_{h}=185 \mathrm{~nm}\right)$ and $C 18$ gemini surfactants $\left(D_{h}\right.$ from 47 to $400 \mathrm{~nm}$ ) at concentrations five times superior to the $\mathrm{cmc}$ are much higher than the length of the straight conformation of the hydrophobic surfactant alkyl chain, estimated to be ca. 1.7 and $2.4 \mathrm{~nm}$ for $\mathrm{C} 12$ and $\mathrm{C} 18$, respectively [65]. This fact indicates that small micelle-like aggregates (spherical micelles) do not occur in these systems and that these surfactants may form vesicle-like aggregates spontaneously when self- aggregation occurs.

\section{Conclusions}

A systematic study of the aggregation properties of quaternary ammonium gemini surfactants with long alkyl chains and different flexible and rigid spacers in aqueous solution was carried out. The effect of the nature and structure of the spacer between the two polar head groups of a series of gemini surfactants with the same hydrophobic chains and approximately the same length of spacer was investigated through electrochemical and spectroscopic techniques. All the investigated gemini surfactants form aggregates at concentrations significantly lower than those corresponding to monomeric surfactants 
containing the same head and tail groups. The lengthening of the hydrophobic alkyl chain from 12 to 18 carbon atoms causes a significant decrease in the critical micelle concentration of the gemini surfactants that depends on the structure of the spacer. The structure of the spacer, flexible or rigid chain, has been found to be a critical parameter on the self-assembly of the gemini surfactant molecules. Gemini surfactants with C18 chains and flexible spacers form micelles at a concentration range 15-50 times lower than that of comparable $\mathrm{C} 12$ analogues whereas the effect of the elongation of the alkyl chain on the $\mathrm{cmc}$ becomes less pronounced for gemini surfactants with rigid $p$-xylyl spacer. As the hydrophilicity of the flexible spacer group increases, the $\mathrm{cmc}$ of gemini surfactants also increases. The QSB3-12 trimeric surfactant displays higher tendency to aggregate than its analogous QSB2-12 gemini surfactant indicating that the incorporation of the additional hydrophobic alkyl chain promotes the self-assembly of the trimeric molecules despite the strong electrostatic repulsion among multiple quaternary ammonium head groups. Spherical micelles are spontaneously formed by $\mathrm{C} 12$ gemini surfactants above the $\mathrm{cmc}$, whereas trimeric and $\mathrm{C} 18$ gemini surfactants form vesicle-like aggregates when self-aggregation occurs.

We have obtained new results on the aggregation behavior of long-chain gemini surfactants which complement the literature data and provide insight into the effect of the alkyl chain length and the nature and structure of the spacer on their self-assembly in aqueous solution. The gemini and trimeric surfactants investigated show superior aggregation properties than monomeric analogues making them more effective surfactants for surface protection. 


\section{ACKNOLEDGEMENTS}

This work has been supported by the Spanish Ministerio de Economia y Competitividad (CTQ2013-41514-P) and the National Center for Research and Development (Poland; TANG01/266340/NCBR/2015).

O.K. thank European Commission for financial support within Erasmus+ Programme.

\section{REFERENCES}

[1] S.K. Verma, K.K. Ghosh, Micellar and Surface Properties of Some Monomeric Surfactants and a Gemini Cationic Surfactant, J. Surfactants Deterg. 14 (2011) 347-352. doi:10.1007/s11743-0101237-0.

[2] U. Tezel, J.A. Pierson, S.G. Pavlostathis, Fate and effect of quaternary ammonium compounds on a mixed methanogenic culture, Water Res. 40 (2006) 3660-3668. doi:10.1016/j.watres.2006.06.019.

[3] F.P. Duval, R. Zana, G.G. Warr, Adsorbed layer structure of cationic gemini and corresponding monomeric surfactants on mica, Langmuir. 22 (2006) 1143-1149.

[4] J. Wçgrzyńska, J. Chlebicki, Preparation, surface-active and antielectrostatic properties of multiple quaternary ammonium salts, J. Surfactants Deterg. 9 (2006) 221-226.

[5] F.M. Menger, J.S. Keiper, Surface-active and antielectrostatic properties of multiple quaternary ammonium salts, Angew. Chem. Int. Ed. 39 (2000) 1906-1920. doi:10.1002/1521-

3773(20000602)39:11<1906::AID-ANIE1906>3.0.CO;2-Q.

[6] R. Zana, J. Xia, Gemini surfactants: synthesis, interfacial and solution-phase behavior, and applications, Marcel Dekker, New York, 2004.

http://www.chemlibnetbase.com/ejournals/books/book_km.asp?id=2399 (accessed November $5,2016)$.

[7] D. Shukla, V.K. Tyagi, Cationic gemini surfactants: a review, J. Oleo Sci. 55 (2006) 381-390. doi:10.56500/jos.55.381.

[8] R. Zana, Dimeric (Gemini) Surfactants: Effect of the Spacer Group on the Association Behavior in Aqueous Solution, J. Colloid Interface Sci. 248 (2002) 203-220. doi:10.1006/jcis.2001.8104.

[9] N.A. Negm, M.F. Zaki, M.A.I. Salem, Antibacterial and Antifungal Activities-Surface Active Properties Relation of Novel Dischiff Base Cationic Gemini Amphiphiles Bearing Homogeneous Hydrophobes, J. Dispers. Sci. Technol. 31 (2010) 1390-1395. doi:10.1080/01932690903269784.

[10] L.L. Schramm, E.N. Stasiuk, D.G. Marangoni, Surfactants and their applications, Annu Rep Prog Chem Sect C Phys Chem. 99 (2003) 3-48. doi:10.1039/B208499F.

[11] M.T. Garcia, O. Kaczerewska, I. Ribosa, B. Brycki, P. Materna, M. Drgas, Biodegradability and aquatic toxicity of quaternary ammonium-based gemini surfactants: Effect of the spacer on their ecological properties, Chemosphere. 154 (2016) 155-160. doi:10.1016/j.chemosphere.2016.03.109.

[12] W.-S. Liu, C.-H. Wang, J.-F. Sun, G.-G. Hou, Y.-P. Wang, R.-J. Qu, Synthesis, Characterization and Antibacterial Properties of Dihydroxy Quaternary Ammonium Salts with Long Chain Alkyl Bromides, Chem. Biol. Drug Des. 85 (2015) 91-97. doi:10.1111/cbdd.12427.

[13] H. Xing, P. Yan, K.-S. Zhao, J.-X. Xiao, Effect of Headgroup Size on the Thermodynamic Properties of Micellization of Dodecyltrialkylammonium Bromides, J. Chem. Eng. Data. 56 (2011) 865-873. doi:10.1021/je100598x.

[14] X. Wang, J. Wang, Y. Wang, H. Yan, P. Li, R.K. Thomas, Effect of the Nature of the Spacer on the Aggregation Properties of Gemini Surfactants in an Aqueous Solution, Langmuir. 20 (2004) 5356. doi:10.1021/la0351008. 
[15] A. Laschewsky, K. Lunkenheimer, R.H. Rakotoaly, L. Wattebled, Spacer effects in dimeric cationic surfactants, Colloid Polym. Sci. 283 (2005) 469-479. doi:10.1007/s00396-004-1219-8.

[16] B. Li, Q. Zhang, Y. Xia, Z. Gao, Surface properties and aggregation behavior of cationic gemini surfactants with dipropylammonium head-groups, Colloids Surf. Physicochem. Eng. Asp. 470 (2015) 211-217. doi:10.1016/j.colsurfa.2015.02.005.

[17] I. Aiad, M.M. El-Sukkary, E.A. Soliman, M.Y. El-Awady, S.M. Shaban, Characterization, surface properties and biological activity of new prepared cationic surfactants, J. Ind. Eng. Chem. 20 (2014) 1633-1640. doi:10.1016/j.jiec.2013.08.010.

[18] M.C. Murguía, M.D. Cristaldi, A. Porto, J.D. Conza, R.J. Grau, Synthesis, Surface-Active Properties, and Antimicrobial Activities of New Neutral and Cationic Trimeric Surfactants, J. Surfactants Deterg. 11 (2008) 41-48. doi:10.1007/s11743-007-1052-4.

[19] Q. Zhang, Z. Gao, F. Xu, S. Tai, Effect of hydrocarbon structure of the headgroup on the thermodynamic properties of micellization of cationic gemini surfactants: An electrical conductivity study, J. Colloid Interface Sci. 371 (2012) 73-81. doi:10.1016/j.jcis.2011.12.076.

[20] M. Hajy Alimohammadi, S. Javadian, H. Gharibi, A. reza Tehrani-Bagha, M.R. Alavijeh, K. Kakaei, Aggregation behavior and intermicellar interactions of cationic Gemini surfactants: Effects of alkyl chain, spacer lengths and temperature, J. Chem. Thermodyn. 44 (2012) 107-115. doi:10.1016/j.jct.2011.08.007.

[21] S.D. Wettig, C. Wang, R.E. Verrall, M. Foldvari, Thermodynamic and aggregation properties of aza- and imino-substituted gemini surfactants designed for gene delivery, Phys Chem Chem Phys. 9 (2007) 871-877. doi:10.1039/B613269C.

[22] N. Kumar, R. Tyagi, Industrial Applications of Dimeric Surfactants: A Review, J. Dispers. Sci. Technol. 35 (2014) 205-214. doi:10.1080/01932691.2013.780243.

[23] A. Singh, J.D. Van Hamme, O.P. Ward, Surfactants in microbiology and biotechnology: Part 2. Application aspects, Biotechnol. Adv. 25 (2007) 99-121. doi:10.1016/j.biotechadv.2006.10.004.

[24] T. Ivanković, J. Hrenović, Surfactants in the Environment, Arch. Ind. Hyg. Toxicol. 61 (2010). doi:10.2478/10004-1254-61-2010-1943.

[25] A. Barhoum, H. Rahier, R.E. Abou-Zaied, M. Rehan, T. Dufour, G. Hill, A. Dufresne, Effect of Cationic and Anionic Surfactants on the Application of Calcium Carbonate Nanoparticles in Paper Coating, ACS Appl. Mater. Interfaces. 6 (2014) 2734-2744. doi:10.1021/am405278j.

[26] N.A. Negm, I.A. Aiad, Synthesis and Characterization of Multifunctional Surfactants in Oil-Field Protection Applications, J. Surfactants Deterg. 10 (2007) 87-92. doi:10.1007/s11743-007-10168.

[27] Y. Xue, H. Xiao, Y. Zhang, Antimicrobial Polymeric Materials with Quaternary Ammonium and Phosphonium Salts, Int. J. Mol. Sci. 16 (2015) 3626-3655. doi:10.3390/ijms16023626.

[28] M.N. Maithufi, D.J. Joubert, B. Klumperman, Application of Gemini Surfactants as Diesel Fuel Wax Dispersants, Energy Fuels. 25 (2011) 162-171. doi:10.1021/ef1006287.

[29] J.R. Akbar, Pharmaceutical applications of gemini surfactants, (2011). https://uwspace.uwaterloo.ca/handle/10012/5700 (accessed November 5, 2016).

[30] http://wwww.cersana.com/en/market-studies/chemicals/surfactants, (2015).

[31] M.A. Hegazy, S.M. Rashwan, M.M. Kamel, M.S. El Kotb, Synthesis, surface properties and inhibition behavior of novel cationic gemini surfactant for corrosion of carbon steel tubes in acidic solution, J. Mol. Liq. 211 (2015) 126-134. doi:10.1016/j.molliq.2015.06.051.

[32] Q. Zhang, Z. Gao, F. Xu, X. Zou, Adsorption and corrosion inhibitive properties of gemini surfactants in the series of hexanediyl-1,6-bis-(diethyl alkyl ammonium bromide) on aluminium in hydrochloric acid solution, Colloids Surf. Physicochem. Eng. Asp. 380 (2011) 191-200. doi:10.1016/j.colsurfa.2011.02.035.

[33] M.A. Malik, M.A. Hashim, F. Nabi, S.A. Al-Thabaiti, Z. Khan, Anti-corrosion ability of surfactants: a review, Int J Electrochem Sci. 6 (2011) 1927-1948.

[34] M. Mahdavian, A.R. Tehrani-Bagha, K. Holmberg, Comparison of a Cationic Gemini Surfactant and the Corresponding Monomeric Surfactant for Corrosion Protection of Mild Steel in Hydrochloric Acid, J. Surfactants Deterg. 14 (2011) 605-613. doi:10.1007/s11743-011-1252-9. 
[35] S.M. Tawfik, A.A. Abd-Elaal, I. Aiad, Three gemini cationic surfactants as biodegradable corrosion inhibitors for carbon steel in $\mathrm{HCl}$ solution, Res. Chem. Intermed. 42 (2016) 11011123. doi:10.1007/s11164-015-2076-4.

[36] N.A. Negm, Y.M. Elkholy, F.M. Ghuiba, M.K. Zahran, S.A. Mahmoud, S.M. Tawfik, Benzothiazol3-ium Cationic Schiff Base Surfactants: Synthesis, Surface Activity and Antimicrobial Applications against Pathogenic and Sulfur Reducing Bacteria in Oil Fields, J. Dispers. Sci. Technol. 32 (2011) 512-518. doi:10.1080/01932691003756902.

[37] B. Brycki, I. Kowalczyk, A. Kozirog, Synthesis, Molecular Structure, Spectral Properties and Antifungal Activity of Polymethylene- $\alpha, \omega$-bis( $N, N$ - dimethyl-N-dodecyloammonium Bromides), Molecules. 16 (2011) 319-335. doi:10.3390/molecules16010319.

[38] A. Laschewsky, K. Lunkenheimer, R.H. Rakotoaly, L. Wattebled, Spacer effects in dimeric cationic surfactants, Colloid Polym. Sci. 283 (2005) 469-479. doi:10.1007/s00396-004-1219-8.

[39] L. Mivehi, R. Bordes, K. Holmberg, Adsorption of Cationic Gemini Surfactants at Solid Surfaces Studied by QCM-D and SPR: Effect of the Rigidity of the Spacer, Langmuir. 27 (2011) 75497557. doi:10.1021/la200539a.

[40] K.P. Minbiole, K.L. Caran, K.N. Seifert, Antimicrobial amphiphiles and methods for their use, WO2012054695, 2012.

[41] M. Borse, V. Sharma, V.K. Aswal, N.K. Pokhriyal, J.V. Joshi, P.S. Goyal, S. Devi, Small angle neutron scattering and viscosity studies of micellar solutions of bis-cationic surfactants containing hydroxyethyl methyl quaternary ammonium head groups, Phys. Chem. Chem. Phys. 6 (2004) 3508. doi:10.1039/b402767c.

[42] T. Asakawa, S. Miyagishi, Demicellization of Sodium Perfluorooctanoate and Dodecyl Sulfate Mixtures Revealed by Pyrene Fluorescence Quenching., Langmuir. 15 (1999) 3464-3468. doi:10.1021/LA981513A.

[43] P.C. Shanks, E.I. Franses, Estimation of micellization parameters of aqueous sodium dodecyl sulfate from conductivity data, J. Phys. Chem. 96 (1992) 1794-1805.

[44] A. Cornellas, L. Perez, F. Comelles, I. Ribosa, A. Manresa, M.T. Garcia, Self-aggregation and antimicrobial activity of imidazolium and pyridinium based ionic liquids in aqueous solution, J. Colloid Interface Sci. 355 (2011) 164-171.

[45] M.T. Garcia, E. Campos, J. Sanchez-Leal, F. Comelles, Structure-activity relationships for sorption of alkyl trimethyl ammonium compounds on activated sludge, Tenside Surfactants Deterg. 41 (2004) 235-239.

[46] A. Mozrzymas, B. Różycka-Roszak, Prediction of critical micelle concentration of cationic surfactants using connectivity indices, J. Math. Chem. 49 (2011) 276-289. doi:10.1007/s10910010-9738-7.

[47] A. Laschewsky, L. Wattebled, M. Arotçaréna, J.-L. Habib-Jiwan, R.H. Rakotoaly, Synthesis and properties of cationic oligomeric surfactants, Langmuir. 21 (2005) 7170-7179.

[48] M.T. Garcia, E. Campos, J. Sanchez-Leal, F. Comelles, Sorption of alkyl benzyl dimethyl ammonium compounds by activated sludge, J. Dispers. Sci. Technol. 27 (2006) 739-744. doi:10.1080/01932690600662554.

[49] M.S. Borse, S. Devi, Importance of head group polarity in controlling aggregation properties of cationic gemini surfactants, Adv. Colloid Interface Sci. 123-126 (2006) 387-399. doi:10.1016/j.cis.2006.05.017.

[50] L. Grosmaire, M. Chorro, C. Chorro, S. Partyka, R. Zana, Alkanediyl- $\alpha, \omega-$ Bis(dimethylalkylammonium Bromide) Surfactants, J. Colloid Interface Sci. 246 (2002) 175-181. doi:10.1006/jcis.2001.8001.

[51] S.D. Wettig, X. Li, R.E. Verrall, Thermodynamic and Aggregation Properties of Gemini Surfactants with Ethoxylated Spacers in Aqueous Solution., Langmuir. 19 (2003) 3666-3670. doi:10.1021/la0340100.

[52] M.J. Rosen, J.T. Kunjappu, Surfactants and Interfacial Phenomena, Fourth Edition., Wiley, 2012.

[53] R. Zana, Alkanediyl- $\alpha, \omega$-bis(dimethylalkylammonium bromide) Surfactants, J. Colloid Interface Sci. 246 (2002) 182-190. doi:10.1006/jcis.2001.7921. 
[54] X. Wang, J. Wang, Y. Wang, H. Yan, P. Li, R.K. Thomas, Effect of the Nature of the Spacer on the Aggregation Properties of Gemini Surfactants in an Aqueous Solution, Langmuir. 20 (2004) 5356. doi:10.1021/la0351008.

[55] X. Li, S.D. Wettig, C. Wang, M. Foldvari, R.E. Verrall, Synthesis and solution properties of gemini surfactants containing oleyl chains., Phys. Chem. Chem. Phys. 7 (2005) 3172-3178. doi:10.1039/b507910a.

[56] Y. Han, Y. Wang, Aggregation behavior of gemini surfactants and their interaction with macromolecules in aqueous solution, Phys. Chem. Chem. Phys. 13 (2011) 1939. doi:10.1039/c0cp01196g.

[57] M.J. Rosen, D.J. Tracy, Gemini surfactants, J. Surfactants Deterg. 1 (1998) 547-554.

[58] D. Jordan, E. Tan, D. Hegh, Synthesis, Characterization and Conductivity of Quaternary Nitrogen Surfactants Modified by the Addition of a Hydroxymethyl Substructure on the Head Group, J. Surfactants Deterg. 15 (2012) 587-592. doi:10.1007/s11743-012-1360-1.

[59] T. Yoshimura, T. Kusano, H. Iwase, M. Shibayama, T. Ogawa, H. Kurata, Star-Shaped Trimeric Quaternary Ammonium Bromide Surfactants: Adsorption and Aggregation Properties, Langmuir. 28 (2012) 9322-9331. doi:10.1021/la301220y.

[60] R. Zana, Critical micellization concentration of surfactants in aqueous solution and free energy of micellization, Langmuir. 12 (1996) 1208-1211.

[61] J. Aguiar, P. Carpena, J.A. Molina-Bolívar, C. Carnero Ruiz, On the determination of the critical micelle concentration by the pyrene 1:3 ratio method, J. Colloid Interface Sci. 258 (2003) 116122. doi:10.1016/S0021-9797(02)00082-6.

[62] N.J. Turro, A. Yekta, Luminescent probes for detergent solutions. A simple procedure for determination of the mean aggregation number of micelles., J. Am. Chem. Soc. 100 (1978) 5951-5952. doi:10.1021/ja00486a062.

[63] M. Pisárčik, J. Jampílek, F. Devínsky, J. Drábiková, J. Tkacz, T. Opravil, Gemini Surfactants with Polymethylene Spacer: Supramolecular Structures at Solid Surface and Aggregation in Aqueous Solution, J. Surfactants Deterg. 19 (2016) 477-486. doi:10.1007/s11743-016-1797-8.

[64] X. Li, S.D. Wettig, R.E. Verrall, Isothermal titration calorimetry and dynamic light scattering studies of interactions between gemini surfactants of different structure and Pluronic block copolymers, J. Colloid Interface Sci. 282 (2005) 466-77.

[65] C. Tanford, Micelle shape and size., J. Phys. Chem. 76 (1972) 3020-4. doi:10.1021/j100665a018. 